\title{
Influence of Cold Rotary Swaging on Microstructure and Uniaxial Mechanical Behavior in Alloy 718
}

\author{
ALEXANDER KLUMPP, ALEXANDER KAUFFMANN, SASCHA SEILS, \\ STEFAN DIETRICH, and VOLKER SCHULZE
}

\begin{abstract}
In this study, the influence of cold rotary swaging on microstructure and mechanical properties of the precipitation-strengthened nickel-based superalloy 718 (Alloy 718) was investigated. The initial stages of work-hardening were characterized by means of microhardness, electron backscatter diffraction (EBSD), and X-ray diffraction (XRD) analyses. Furthermore, attention was devoted to the mechanical behavior at ambient and elevated temperature $\left(550{ }^{\circ} \mathrm{C}\right)$ in uniaxial tension and compression. Rotary swaging to different true strains of maximum $\varphi=0.91$ caused a moderate increase of microhardness and enhanced markedly the load-bearing capacity in tension, giving rise to yield strength beyond $2000 \mathrm{MPa}$. The mechanical strength $R_{p 0.2}$ in tension subsequent to rotary swaging perfectly correlates with increasing dislocation density $\rho$ estimated from XRD in the form of a Taylor-like relationship $R_{p 0.2} \propto \sqrt{\rho}$. In compression, transient stress-strain evolution without the occurrence of a clear elastic range and distinct yield phenomenon was observed. Restoration of the elastic range, accompanied by a pronounced increase of microhardness, was obtained by a post-swaging tempering treatment at $600{ }^{\circ} \mathrm{C}$.
\end{abstract}

https://doi.org/10.1007/s11661-021-06371-w

(C) The Author(s) 2021

\section{INTRODUCTION}

DUE to its outstanding combination of mechanical properties, creep and corrosion resistance, the Nickel-based superalloy 718 (Alloy 718), often referred to as "Inconel 718" or "IN718," has been applied vastly in demanding aerospace, power plant, and petrochemical applications. ${ }^{[1-8]}$ It is commonly utilized as wrought material in precipitation-hardened condition, where it is strengthened mainly by the $\mathrm{D}_{22}$-ordered metastable $\gamma^{\prime \prime}$-phase $\left(\mathrm{Ni}_{3} \mathrm{Nb}\right)$. This phase appears as dispersed ellipsoidal discs of approximately 20 to $40 \mathrm{~nm}$ in diameter and $5 \mathrm{~nm}$ in thickness embedded in the cubic face-centered $\gamma$-matrix. In peak-aged condition, the $\gamma^{\prime \prime}$ phase content is approximately 15 to 20 vol. pet. $^{[9,10]}$ Additional strengthening is obtained by the $\mathrm{L}_{2}$-ordered $\gamma^{\prime}$-phase $\left(\mathrm{Ni}_{3} \mathrm{Al}, \mathrm{Ni}_{3} \mathrm{Ti}\right)$ which is present in the form of spheres of approx. $20 \mathrm{~nm}$ in diameter. Moreover, volume fraction and distribution of the $\mathrm{D} 0_{\mathrm{a}}$-ordered equilibrium orthorhombic $\delta$-phase $\left(\mathrm{Ni}_{3} \mathrm{Nb}\right)$ affect the properties of the material, particularly, in terms of strength and ductility. Thus, the mechanical behavior of

ALEXANDER KLUMPP, ALEXANDER KAUFFMANN, SASCHA SEILS, STEFAN DIETRICH, and VOLKER SCHULZE are with the Institute for Applied Materials (IAM-WK), Karlsruhe Institute of Technology (KIT), Kaiser-straße 12, 76131 Karlsruhe, Germany. Contact e-mail: alexander.klumpp@kit.edu

Manuscript submitted April 21, 2021; accepted June 25, 2021.

Article published online July 28, 2021
Alloy 718 has been studied intensively and various relationships to microstructural properties have been derived. ${ }^{[1,6,7,9]}$

One major influencing factor on microstructural evolution, mechanical features, and resulting service life behavior of Alloy 718 is cold work. The latter can be introduced during various stages of manufacturing before $^{[3-5,8,11,12]}$ or after ${ }^{[6,7,10,13]}$ aging and can be accomplished intentionally (cold rolling, drawing, swaging $^{[10,14,15]}$ ) or rather unintentionally (straightening procedures, mechanical surface treatments. ${ }^{[16,17]}$ )

In a number of investigations, the effects of cold deformation on precipitation behavior and subsequent mechanical properties in solution-annealed Alloy 718 have been studied. ${ }^{[3,5,8,11,12,18]}$ This processing route is relevant to a number of components, such as high strength, high-temperature fasteners, ${ }^{[14]}$ and highly stressed parts in petrochemical applications. ${ }^{[5]}$ For instance, Mei et $a l^{[3]}$ used differential scanning calorimetry (DSC) to investigate the effects of cold rolling with thickness reductions of up to 70 pct on the precipitation kinetics of various phases in Alloy 718 . Extending and confirming earlier investigations, ${ }^{[1,12]}$ they found decreasing $\gamma^{\prime \prime}$ - and $\delta$-peak precipitation temperatures with increasing amount of cold work. However, a decreasing influence of post-deformation aging $\left(800{ }^{\circ} \mathrm{C}\right.$; 8 hours) was found regarding microhardness with increasing degrees of pre-deformation. In addition, the uniaxial mechanical behavior after cold rolling of solution-annealed Alloy 718 was recently 
investigated by Chen et al. ${ }^{[5]}$ and Zhang et al. ${ }^{[8]}$ at room temperature and $650{ }^{\circ} \mathrm{C}$, respectively. Cold rolling with thickness reductions up to 50 pct was found to increase the room-temperature yield strength from approx. $450 \mathrm{MPa}$ to approx. $1370 \mathrm{MPa}$, while the elongation was reduced from approx. 45 to 5 pct. ${ }^{[5]}$ Subsequent aging treatments further enhanced yield strength but reduced the ductility. ${ }^{[5,8]}$ The aforementioned works focused on the implications of cold work applied to Alloy 718 prior to aging.

Only few publications have dealt with microstructure and mechanical behavior of Alloy 718 in precipitation-strengthened and subsequently cold-worked condition. ${ }^{[6,7,10,13,19]}$ If cold deformation is the last step prior to service, knowledge about the cold-worked, local microstructure and mechanical behavior in service is vital for any modeling and predictive purposes. In two studies, Kalluri et al ${ }^{[7,10]}$ investigated the room-temperature low-cycle fatigue behavior of Alloy 718 after uniaxial tensile $(+2 \mathrm{pct} ;+10 \mathrm{pct})$ and compressive ( -2 pct) pre-deformation. Using TEM analysis, they deduced that at large total pre-strains $(+10 \mathrm{pct})$ and small cyclic total strains $\left(\Delta \varepsilon_{t}=0.8 \mathrm{pct}\right)$ in tension deformation may be confined to slip bands which had already been activated during monotonic deformation. Work softening was only found if the cyclic strains were relatively high and was mostly attributed to the wellknown shearing ("scrambling") of $\gamma^{\prime \prime}$-precipitates. ${ }^{[10,20,21]}$ A main feature of the procedure applied by Kalluri et al. is the coincidence of pre-strain direction with the subsequent strain direction, both being uniaxial. However, large degrees of pre-deformation, as they might prevail locally after shaping or finishing treatments, ${ }^{[17]}$ can usually not be achieved by uniaxial tensile deformation. To cope with this shortcoming, Praveen et al. ${ }^{[6,13]}$ applied cold rolling with reductions between 5 and 20 pet to peak-aged Alloy 718 and characterized the resulting mechanical behavior in tension ${ }^{[6]}$ and tension-compression. ${ }^{[13]} \mathrm{Up}$ to $600{ }^{\circ} \mathrm{C}$, the material's yield strength increased considerably ( $\geq 30$ pct) while the effects vanished at temperatures above approx. $650{ }^{\circ} \mathrm{C}$ due to dynamic recovery. Finally, in a recent study, the authors of this work and others investigated the influence of cold rotary swaging on the room-temperature fatigue crack growth behavior in precipitation-strengthened Alloy $718^{[19]}$ and found detrimental effects of cold work on long crack growth rates and thresholds.

Despite those endeavors, the implications of largely spread degrees of cold work on microstructure and mechanical behavior in precipitation-strengthened conditions of Alloy 718 have so far not been assessed. This paper aims at closing this gap. Cold rotary swaging was applied to achieve the different degrees of work-hardening. Stress-strain properties in uniaxial tension and compression are provided for two test temperatures. Furthermore, EBSD and XRD analyses are used with a focus on quantitative microstructural characterization and correlation with the aforementioned mechanical properties. Finally, the changes in mechanical behavior during service are estimated by means of a 100-hour tempering treatment at $600{ }^{\circ} \mathrm{C}$.

\section{EXPERIMENTAL}

\section{A. Material and Specimen Preparation}

Cylindrical rods of Alloy 718 with an initial diameter of $30 \mathrm{~mm}$ and a length of approx. $300 \mathrm{~mm}$ were used for this investigation. The material ("Allvac 718") was purchased from ATI Specialty Materials in the solution-annealed condition according to AMS 5662. The chemical composition of the investigated heat is shown in Table I.

The rods were precipitation-hardened in a muffle furnace according to AMS 5663. First, they were solution-annealed at $954{ }^{\circ} \mathrm{C}$ for 1 hours and subsequently quenched with compressed air. Then, they were aged at $718{ }^{\circ} \mathrm{C}$ for 8 hours, furnace cooled to $621{ }^{\circ} \mathrm{C}$ within 2 hours and aged at $621{ }^{\circ} \mathrm{C}$ for another 8 hours. Figure 1 shows an optical micrograph in transverse direction within the center of a precipitation-hardened rod. Equiaxed $\gamma$-grains with a mean size of approx. $8.8 \mu \mathrm{m}$ were determined by means of the linear intercept method.

Subsequently, a Fritz Werner four punch rotary swaging machine was used to achieve five different degrees of work-hardening in the material. The true plastic strain of

$$
\varphi \equiv\left|\varepsilon_{\mathrm{p}}\right|=\left|\ln \left(\frac{D_{1}^{2}}{D_{0}^{2}}\right)\right|
$$

was chosen $\varphi_{0}=0 \quad$ (as-recrystallized), $\varphi_{1}=0.14$, $\varphi_{2}=0.36, \varphi_{3}=0.62$, and $\varphi_{4}=0.91$. In the formula, $D_{0}$ denotes the initial diameter and $D_{1}$ the diameter after rotary swaging. Deformation temperature was limited to a maximum of approx. $200{ }^{\circ} \mathrm{C}$, which was estimated with regard to the lubricant boiling temperature.

After pre-deformation, specimens for tensile and compression tests were extracted from each of the rods by means of turning. The characterization of tensile behavior was done using the specimen geometry shown in Figure 2(a). Its gauge section was 14 and $7 \mathrm{~mm}$ in length and diameter, respectively. Compression tests were carried out using the cylindrical specimen geometry shown in Figure 2(b). The same sample geometry was used for microstructural characterization.

\section{B. Methods of Analysis}

The work-hardening state after rotary swaging was characterized by means of microhardness measurements, electron backscatter diffraction (EBSD) mapping, and Williamson-Hall analysis.

Vickers microhardness measurements were carried out at $1000 \mathrm{gf}$ ("HV1") on a standard testing device. Using compression samples cut in transverse direction, 15 measurements were carried out on each state.

Scanning electron microscopy (SEM) studies were performed on a Zeiss Auriga 60 system equipped with an EDAX DigiView EBSD system. The samples were cut in longitudinal direction and prepared by a standard metallographic procedure. The final preparation step was vibratory polishing. Orientation maps of $(85 \times$ 85) $\mu \mathrm{m}^{2}$ in size were acquired at a step size of $0.2 \mu \mathrm{m}$ on 
Table I. Chemical Composition of the Investigated Heat of Alloy 718, Given in Wt Pct

\begin{tabular}{lccccccc}
\hline $\mathrm{Ni}$ & $\mathrm{Fe}$ & $\mathrm{Cr}$ & $\mathrm{Nb}$ & $\mathrm{Mo}$ & $\mathrm{Ti}$ & $\mathrm{Al}$ & $\mathrm{C}$ \\
\hline 54.00 & 18.44 & 17.87 & 5.13 & 2.89 & 1.06 & 0.47 & 0.02 \\
\hline
\end{tabular}

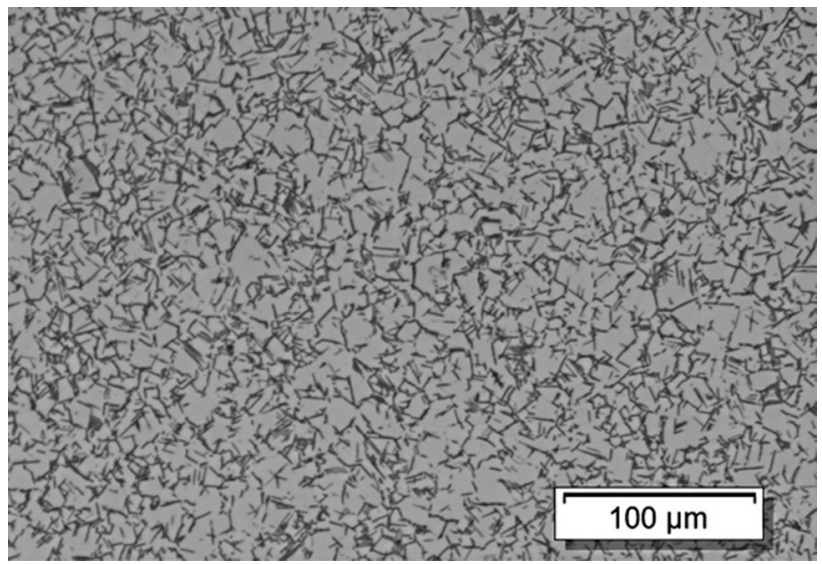

Fig. 1-Microstructure of the investigated heat of Alloy 718 prior to cold working.

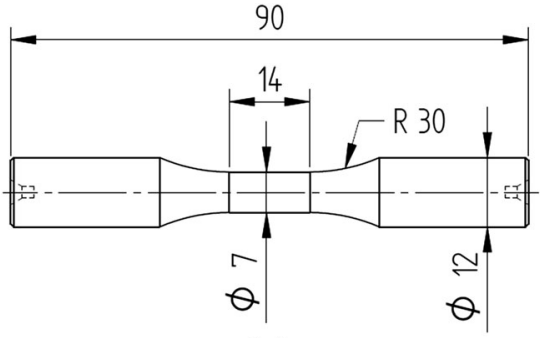

(a)

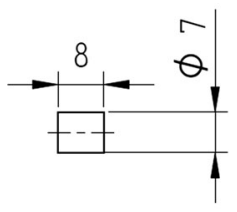

(b)
Fig. 2-Specimen geometries for tensile (a) and compression tests (b); measures in $\mathrm{mm}$.

a hexagonal grid. Kernel average misorientation was calculated from the first perimeter of pixels excluding grain boundaries with misorientations higher than 10 deg.

XRD analyses were carried out on polished longitudinal sections using a Bruker D2 Phaser device equipped with a $\mathrm{Cu} \mathrm{X}$-ray source and a LynxEye line detector. Fluorescence radiation was filtered by proper energy discrimination at the detector. To improve statistics, the samples were rotated during the measurement. Full width at half maximum of individual peaks was determined by deconvolution of the contributions by $K \alpha_{1}$ and $\mathrm{K} \alpha_{2}$.

\section{Mechanical Testing}

An Instron 8803 servo-hydraulic testing machine with closed loop control was used for mechanical testing. Figure 3 shows the test setup overview (a), and the details for uniaxial tension (b) and compression (c) testing. Two temperatures were chosen for the experiments, namely $20^{\circ} \mathrm{C}(293 \mathrm{~K})$ and $550{ }^{\circ} \mathrm{C}(823 \mathrm{~K})$. The latter was achieved and controlled by an inductive heating device and thermocouples of type "K," respectively. The temperature within the gauge length was held constant to $\pm 3 \mathrm{~K}$ for $1200 \mathrm{~s}$ before each experiment.

Forces were measured using an Interface load cell with a maximum load capacity of $100 \mathrm{kN}$. Strain measurements were carried out using an Instron-type strain gauge-based extensometer with an initial gauge length of $12 \mathrm{~mm}$. In tensile tests, the extensometer was directly mounted to the specimens. These tests were conducted in strain control with a constant strain rate of $5 \cdot 10^{-4} \mathrm{~s}^{-1}$. Due to the limited space, direct strain measurements were not possible in compression tests where the specimen length was limited to $8 \mathrm{~mm}$ (see for Figure 2(b)) to avoid buckling. In this case, the tests were conducted with constant crosshead speed and the extensometer was applied to the compression punches. To obtain a measure of the actual strain in the samples, the stiffness of the test setup was determined at $20{ }^{\circ} \mathrm{C}$ and $550{ }^{\circ} \mathrm{C}$ according to

$$
S_{M}=\left(\frac{\Delta F}{\Delta l_{t}-\frac{\Delta F}{E_{s} A_{s}} l_{0, s}}\right),
$$

where $S_{M}, \Delta F, \Delta l_{t}, E_{s}, A_{s}$, and $l_{0, s}$ denote the setup's stiffness, the recorded test force change, the recorded total length change, Young's modulus, cross-sectional area, and initial gauge length of the specimen, respectively. The stiffness evaluation was carried out on the as-recrystallized specimens $\left(\varphi_{0}=0\right)$ in the elastic range. Young's moduli were determined a priori in tensile tests to approx. 200 and $175 \mathrm{GPa}$ at $20{ }^{\circ} \mathrm{C}$ and $550{ }^{\circ} \mathrm{C}$, respectively, and are in satisfying accordance with the literature values. ${ }^{[1]}$

Finally, a small number of compression specimens was used to assess the implications of a tempering treatment for 100 hours at $600{ }^{\circ} \mathrm{C}(873 \mathrm{~K})$ in a muffle furnace. Due to excessive test forces, the specimen size had to be reduced to $5 \mathrm{~mm}$ in diameter and $5.7 \mathrm{~mm}$ in length. To prevent the extensometer from any damage, tests of all kind were stopped at maximum total strains of $\varepsilon_{\mathrm{t}}=4$ to $6 \mathrm{pct}$, depending on material state and test type. During all compression tests, the strain rate was in the order of approx. $2 \sim 6 \cdot 10^{-4} \mathrm{~s}^{-1}$. Compression tests were carried out three to four times. Tensile tests at elevated temperature were carried out twice. Due to the limited number of specimens, tensile tests and ambient temperature could not be repeated.

\section{RESULTS AND DISCUSSION}

\section{A. Material State Characterization}

Table II shows the quantitative microhardness evolution due to cold working. A rapid initial hardness increase with a trend toward saturation is apparent. No influence of the radial position on the samples was found, indicating that the rods were homogeneously cold-worked. 

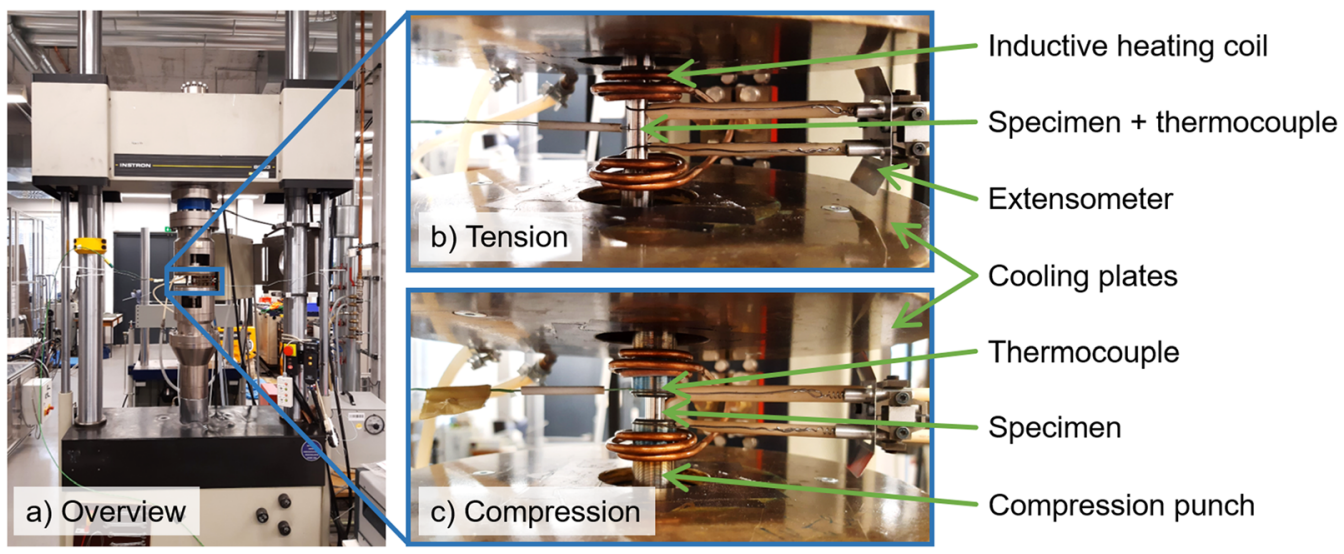

Fig. 3-Applied test setup: overview (a); detail for tensile tests (b); detail for compression tests (c).

In Figures 4 and 5, EBSD maps of longitudinal sections close to the centers of the rods are shown. Figures 4(a) through (c) are color-coded according to the inverse pole figure ("IPF maps") of the rod axis for $\varphi_{0}=0, \varphi_{1}=0.14$, and $\varphi_{4}=0.91$, respectively. Figure 5 shows the corresponding maps of kernel average misorientation ("KAM maps"). The IPF map of the non-deformed state indicates randomly oriented and equiaxed grains. It is obvious from the KAM maps that the plastic deformation in the initial stage of cold working $\left(\varphi_{1}=0.14\right)$ is confined mainly to regions close to grain boundaries. Large amount of deformation $\left(\varphi_{4}=0.91\right)$ causes regions with very large misorientations $(\geq 10 \mathrm{deg})$ close to grain boundaries of the initial microstructure. This is indicative of localized deformation to accommodate the different numbers of active slip systems, for example, eight and six (assuming biaxial compression during rotary swaging) in grains with $\langle 111\rangle$ and $\langle 001\rangle$ directions parallel to the rod axis, respectively. The additional network structure of medium kernel average misorientations in the grain interior fairly evolved at $\varphi_{1}=0.14$ and more pronounced in certain orientations for $\varphi_{4}=0.91$ is most probably attributed to localized deformation due to shearing of ellipsoidal plate-like $\gamma^{\prime \prime}$ precipitates $^{[10,20,21]}$ that are typically aligned with $\{100\}$ planes of the $\gamma$-matrix. ${ }^{[9]}$ From Figure 4 , it can also be derived that a mixed fiber texture with $\langle 111\rangle$ and $\langle 001\rangle$ directions parallel to the rod axis is formed by severe deformation. Fiber textures are a typical result of axisymmetric deformation in cubic face-centered materials. ${ }^{[22]}$ Furthermore, grain elongation along the rod axis is caused by severe plastic deformation. Confirming the observations in the present study, Liu et al. ${ }^{[11]}$ found stretched grains after cold rolling of Alloy 718 with reductions above 25 pct.

In Figure 6, the distribution of KAM in the recrystallized state with almost no geometrically necessary dislocations is compared to the condition with low pre-strain of $\varphi_{1}=0.14$ and with the maximum prestrain of $\varphi_{4}=0.91$. In the recrystallized state, the distribution is narrow and of (almost) log-normal character. The KAM of maximum frequency in this condition is determined by the orientation resolution of the EBSD system in use of about $0.3 \mathrm{deg}$.
The distribution becomes much broader and the KAM of maximum frequency increases due to the incorporation of geometrically necessary dislocations. The maximum frequency of KAM is observed at about 0.5 and $1.4 \mathrm{deg}$ for $\varphi_{1}=0.14$ and $\varphi_{4}=0.91$, respectively.

The total dislocation density, taking both geometrically necessary and statistically stored dislocations into account, can be estimated by means of X-ray line broadening analysis. Figure 7 shows the XRD diffraction patterns of the initial recrystallized and aged condition in comparison to the condition at maximum pre-strain. Obviously, the peak intensity of sets of lattice planes close to $\{\mathrm{hhh}\}$ and $\{\mathrm{h} 00\}$ is reduced in the maximum pre-strained condition due to $\langle 111\rangle /\langle 001\rangle$ fiber texture along the rod axis.

Figure 8(a) depicts the peak width as a function of peak position deduced from XRD patterns (Figure 7) and expressed in terms of the scattering vector $s=$ $2 \sin \Theta / \lambda$ and $\Delta s=\Delta 2 \Theta \cos \Theta / \lambda$ with $\Theta$ being the peak position, $\Delta 2 \Theta$ the full width at half maximum of the $K \alpha_{1}$ peaks, and $\lambda$ the $(\mathrm{Cu}) \mathrm{X}$-ray wave length of $1.5406 \AA$. It is clearly seen that the peaks significantly broaden by the applied deformation. The extent of line broadening strongly depends on the diffracting set of lattice planes due to elastic anisotropy and varying contrast factors for dislocations. Hence, dislocation density is estimated after correcting for elastic anisotropy ${ }^{[23]}$ and instrumental broadening (analysis of an $\mathrm{LaB}_{6}$ reference powder) in Figure 8(b). Elastic anisotropy was corrected by normalizing the scattering vector $s$ by the direction-specific Young's moduli $E_{h k l}$. These were calculated in the direction perpendicular to the respective set of lattice planes $\{h k l\}$ on the basis of anisotropic elastic compliances of IN718 $C_{11}, C_{12}$, and $C_{44}$ of 244, 155, and $111 \mathrm{GPa}$, respectively. ${ }^{[24]}$ The slopes $m$ in Figure 8(b) are indicative of the magnitude of the estimated dislocation density $\rho$ and scale proportional to its square $\operatorname{root}^{[25]}$.

$$
m \propto E b \sqrt{\rho}
$$

$b$ and $E$ denote the length of the Burgers vector and the Young's modulus, respectively. An increase of the estimated dislocation density by almost 1.5 orders of magnitude from the as-recrystallized state to a pre-strain 
Table II. Microhardness (HV1) Evolution After Rotary Swaging

\begin{tabular}{lrrrrr}
\hline True strain $\varphi / 1$ & 0 & 0.14 & 0.36 & 0.62 & 0.91 \\
\hline Microhardness / HV1 & 469.8 & 505.9 & 530.1 & 535.6 & 542.6 \\
Standard deviation / HV1 & 7.6 & 4.2 & 4.6 & 4.3 \\
\hline
\end{tabular}
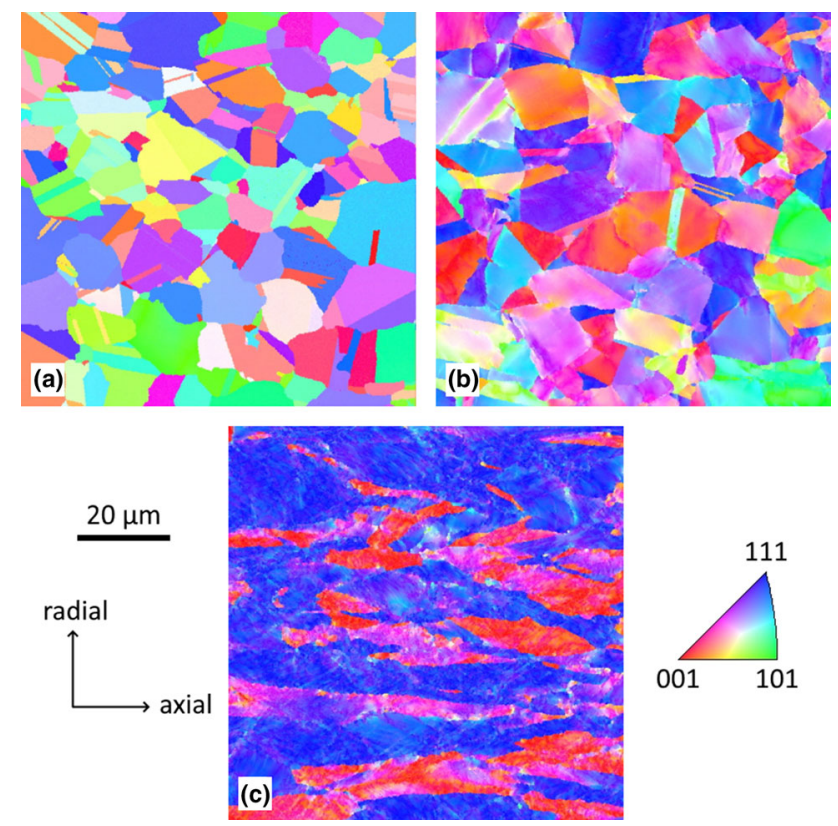

Fig. 4-Longitudinal IPF maps of different true strains of $\varphi_{0}=0$ $(a), \varphi_{1}=0.14(b)$ and $\varphi_{4}=0.91(c)$. Magnification is the same for all three micrographs. Color code corresponds to the inverse pole figure of the rod axis and is depicted as standard triangle (Color figure online).
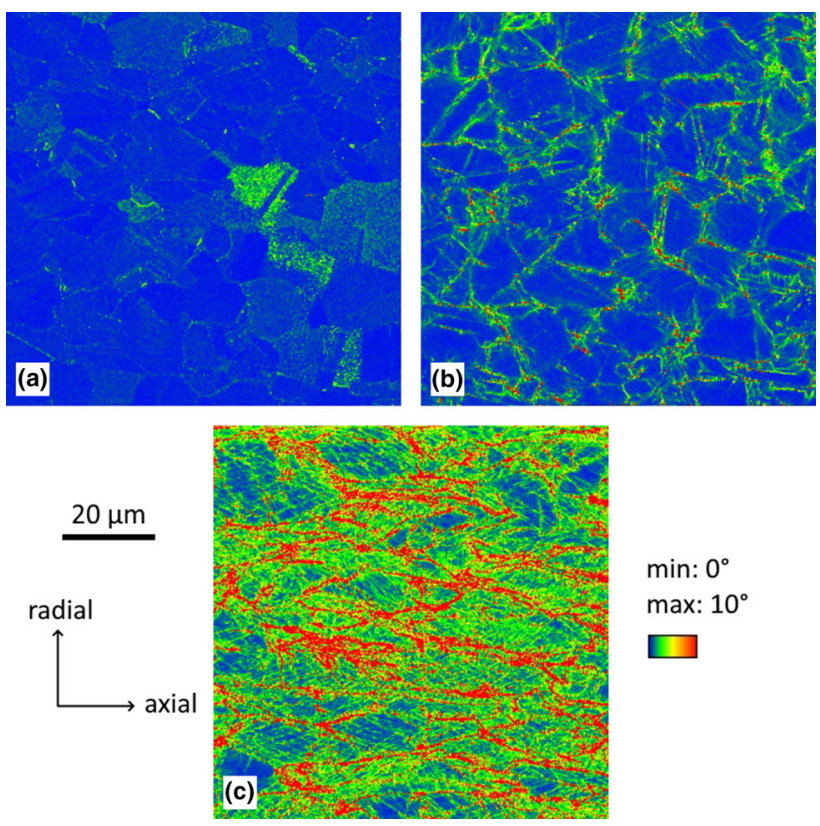

Fig. 5-Longitudinal KAM maps of different true strains of $\varphi_{0}=0$ $(a), \varphi_{1}=0.14(b)$ and $\varphi_{4}=0.91(c)$. Same regions are mapped as in Figure 4.

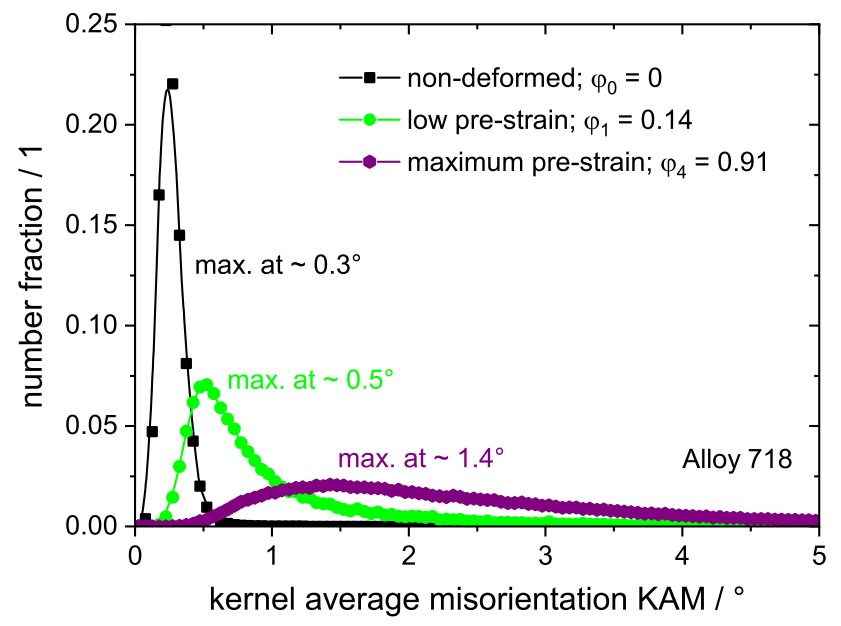

Fig. 6-Distribution of KAM obtained from Figure 5.

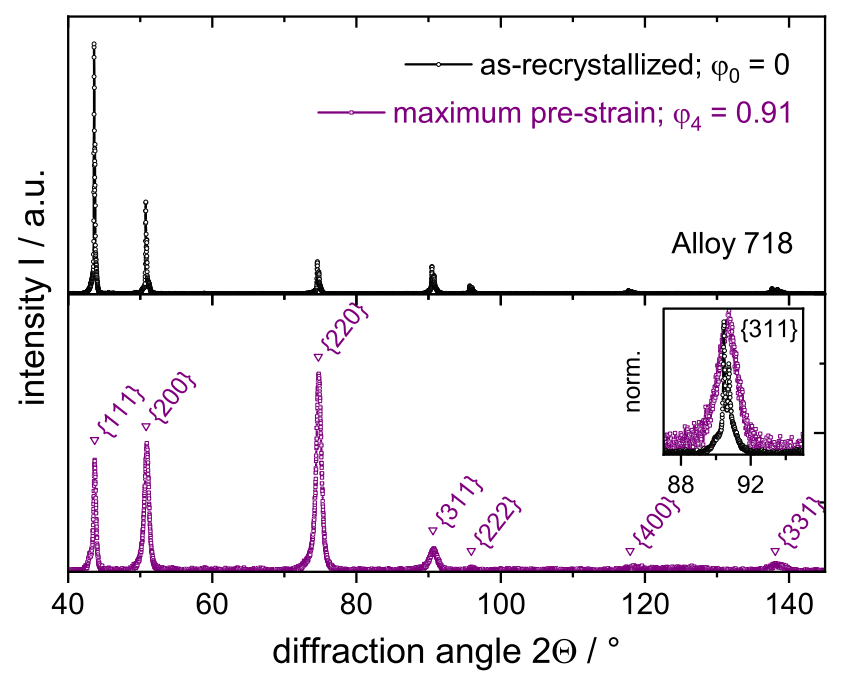

Fig. 7-XRD diffraction pattern of undeformed $\left(\varphi_{0}=0\right)$ and severely deformed $\left(\varphi_{4}=0.91\right)$ Alloy 718 .

of $\varphi_{1}=0.14$ is observed as well as another increase of only 0.5 order of magnitude when deforming up to $\varphi_{4}=0.91$. The influence of lattice strain by semi-coherent precipitates, e.g., $\gamma^{\prime \prime}$, is considered approximately the same throughout the sample series due to precipitation prior to rotary swaging.

\section{B. Uniaxial Tensile and Compression Tests}

Figures 9 and 10 show the stress-strain curves derived from uniaxial tensile tests at ambient and elevated temperature, respectively. A pronounced flow stress increase due to the preceding work-hardening can be 


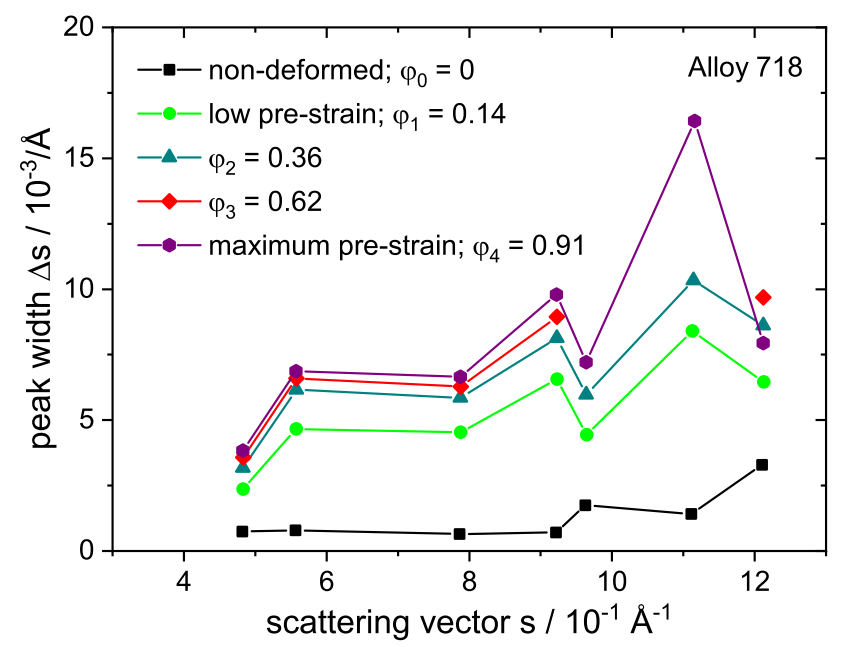

(a)

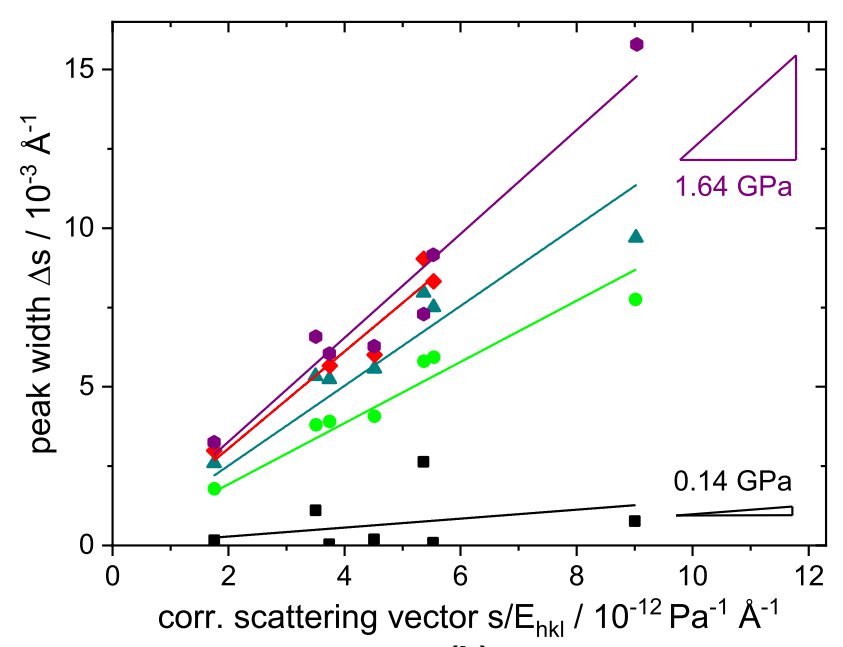

(b)

Fig. 8-Evaluation of XRD peak width: (a) $\Delta s$ as a function of scattering vector $s$. Connecting lines are to guide the eyes. (b) Correction for elastic anisotropy and instrumental broadening. Slopes indicated in (b) are proportional to the square of the estimated dislocation density $\rho$. Note that $\{222\}$ and $\{400\}$ diffraction peaks weak in intensity due to texture and broad due to defect density are omitted if evaluation was not reasonable.

seen in both cases. In the flow curves of cold-worked conditions, deviations from linear elastic behavior can be found already above about $1100 \mathrm{MPa}$ (ambient temperature) and $900 \mathrm{MPa}$ (elevated temperature). In any case of pre-deformation, only a very short period of uniform deformation was found prior to necking.

Figures 11 and 12 show the stress-strain curves in uniaxial compression at room and elevated temperatures, respectively. For the sake of better comparability with tensile test results, the magnitudes (i.e., positive values) of engineering total strains and stresses are depicted. At ambient temperature, distinct elastic regions can only be seen in stress-strain relationships of the non-swaged material. Regardless of the degree of pre-deformation, the previously swaged material conditions yield almost instantly, resulting in non-linear stress-strain relationships. However, the degree of

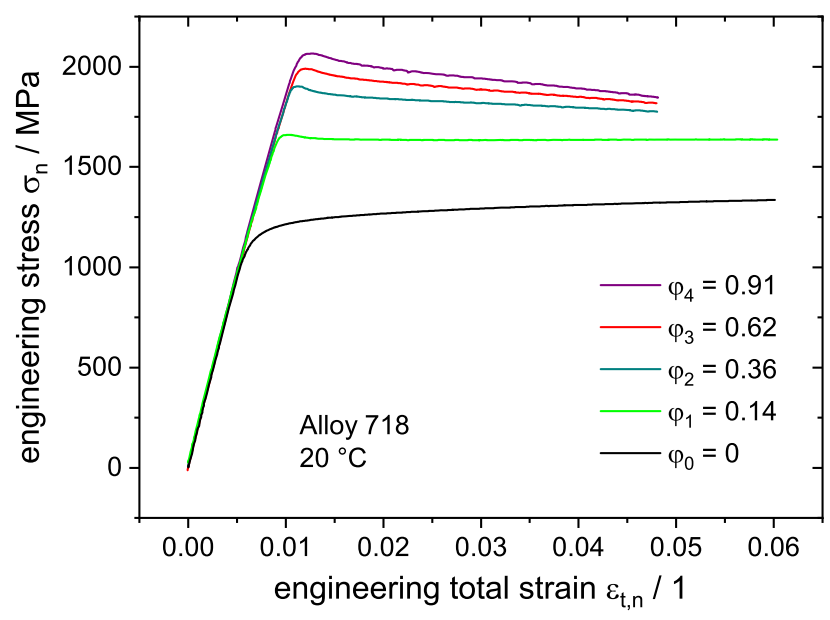

Fig. 9-Results of tensile tests at $20^{\circ} \mathrm{C}$.

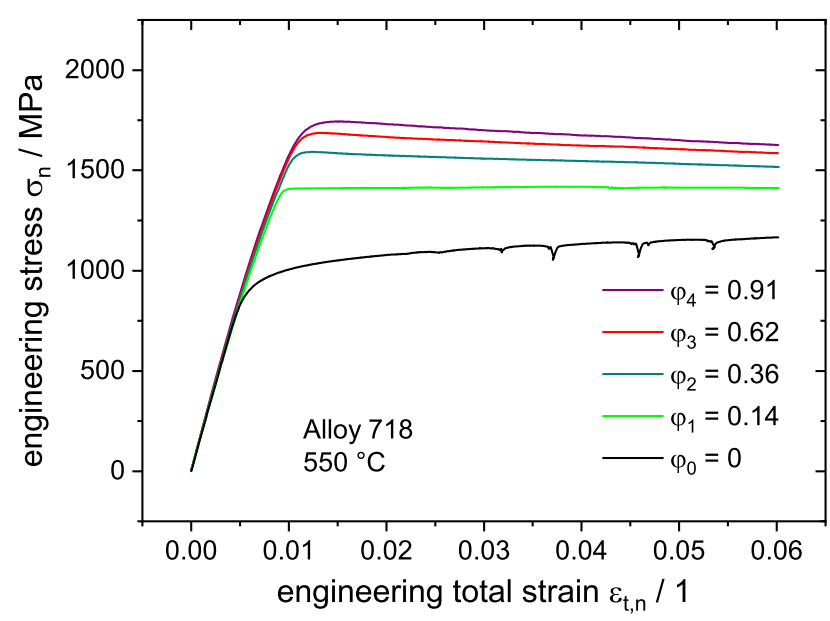

Fig. 10 - Results of tensile tests at $550{ }^{\circ} \mathrm{C}$.

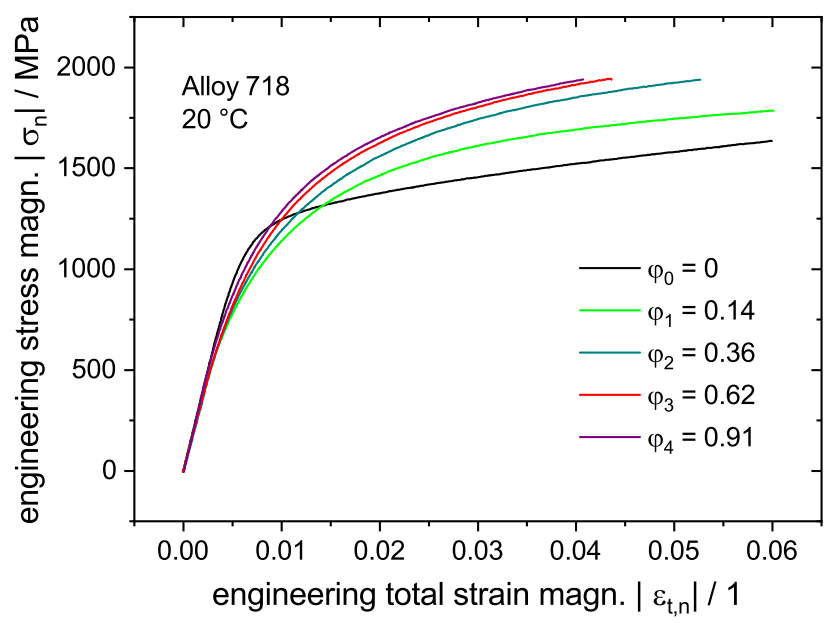

Fig. $11-$ Results of compression tests at $20^{\circ} \mathrm{C}$.

subsequent hardening exceeds the strain-hardening of the non-swaged state. In contrast, at elevated temperatures the elastic region can obviously be restored. After 


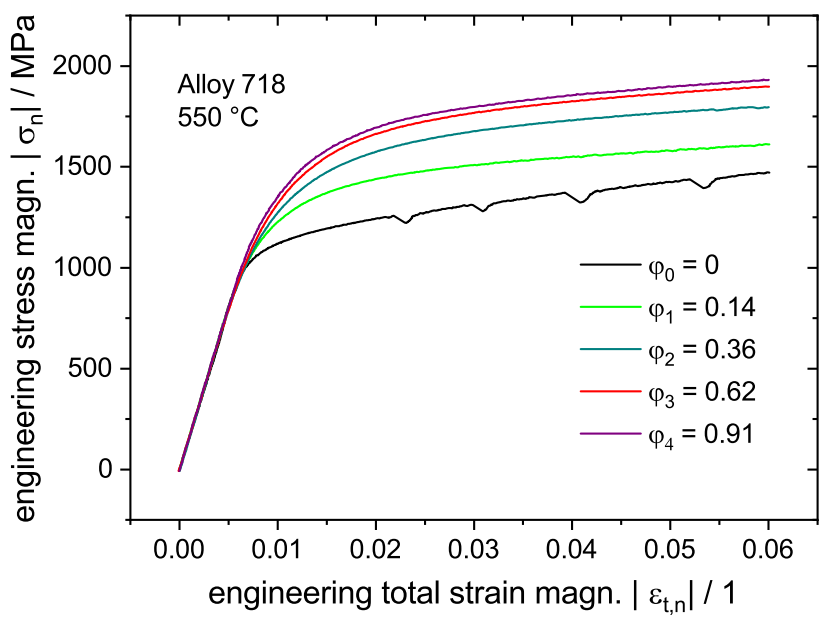

Fig. 12 - Results of compression tests at $550{ }^{\circ} \mathrm{C}$.

a period of increasing hardening rate with increasing pre-deformation, the strain-hardening rate of the cold-worked states becomes similar to the strain-hardening rate of the as-recrystallized state.

Both, in compression and tension, serrations appear in the stress-strain curves of the non-swaged state during deformation at $550{ }^{\circ} \mathrm{C}$. The effect vanishes after pre-deformation.

Besides the obvious effect of increasing flow stresses due to work-hardening, it can be seen from the results of ambient temperature tests that after cold rotary swaging neither in tension nor in compression distinct yield points can be obtained from the deformation curves. While in compression no elastic region can be observed at all regardless of pre-deformation, the tensile tests exhibit increasing deviations from linearity with increasing stresses. This can be attributed to a superposition of several effects, namely residual stress formation, (residual) stress relaxation and Bauschinger effect. The absence of clear yield points after cold working indicates that macroscopic residual stresses (type ${ }^{[26]}$ ) in longitudinal (axial) direction may prevail. $\left.{ }^{[13,2}\right]$ With residual stresses present, specimen sections with tensile (compressive) residual stress yield earlier under tensile (compressive) loads than the section with opposed residual stress. As axial and tangential residual stresses are a common by-product of the rotary swaging process, ${ }^{[28]}$ they help explain the non-linearities found in tension. Additionally, recovery and relaxation of residual stresses under applied load may occur at elevated temperatures. ${ }^{[17,27]}$ In particular, large degrees of cold work promote thermally activated residual stress relaxation in Alloy $718 .^{[17]}$ Exposing shot-peened Alloy 718 with an estimated near-surface cold work of 30 pct at $525{ }^{\circ} \mathrm{C}(798 \mathrm{~K})$, residual stresses were found to relax by more than $50 \mathrm{pct}$ within only 10 minutes. ${ }^{[17]}$ It is therefore deduced that particularly for high degrees of work-hardening, residual stresses relax to a large degree already during the 20-minutes soaking period at $550{ }^{\circ} \mathrm{C}$, accompanied by a certain degree of recovery. In addition, stress relaxation during testing is likely to occur. However, the immediate onset of plastic deformation in compression at ambient temperature can only be rationalized by consideration of the Bauschinger effect, particularly its transient portion. ${ }^{[2-32]}$ The latter denotes decreased resistance against plastic deformation in the direction opposite to preceding deformation. It is mainly owed to the presence of mobile dislocations with directionality in their resistance to motion and supported by annihilation of dislocations during reverse deformation. ${ }^{[29]}$ In contrast, the permanent softening contribution to the Bauschinger effect is closely related to the decay and reformation of longer-range internal stress fields upon strain reversal. ${ }^{[31]}$ At room temperature, Alloy 718 is known to exhibit inhomogeneous deformation by planar slip. ${ }^{[6,20,21]}$ Accordingly, the prevalence of planar slip bands after cold rolling (5 pct reduction in area) could be shown using TEM analysis ${ }^{[6]}$ and confirmed for deformation up to $\varphi=0.62$ (46 pct reduction in area) by cold rotary swaging. ${ }^{[19]}$ Such planar dislocation structures, accompanied by precipitates prone to slip transmission, promote the Bauschinger effect. ${ }^{[30]}$ Results in support of residual stress formation and Bauschinger effect were found in studies by Kalluri et al. ${ }^{[7,10]}$ and Praveen et al. ${ }^{[6,13]}$ in precipitation-strengthened Alloy 718. The material was pre-strained by means of uniaxial tension and cold rolling, respectively. In cyclic tests, tensile (compressive) pre-strain caused tensile (compressive) mean stress, ${ }^{[7]}$ as may be expected after uniaxial pre-deformation. In the case of cold rolling, mean stress formation was explained in terms of residual stresses. ${ }^{[6]}$ As explained above, a combination of effects is more likely to prevail. The observed (partial) restoration of the elastic range in compression at $550{ }^{\circ} \mathrm{C}$ can be attributed to static strain aging, ${ }^{[30]}$ i.e., the pinning of mobile dislocations by diffusing elements. ${ }^{[33,34]}$ Yet, stress magnitudes at the onset of plastic deformation are still significantly below those measured at $550{ }^{\circ} \mathrm{C}$ in tension. Mataya et al. ${ }^{[30]}$ investigated the Bauschinger effect in $\mathrm{N}$-strengthened austenitic steel exhibiting planar slip at ambient temperature and wavy slip at an elevated temperature of $480{ }^{\circ} \mathrm{C}(753 \mathrm{~K})$. They found that sole stress-relief of the material reduced the transient portion of the Bauschinger effect, while permanent softening was only suppressed when the prior deformation had occurred in a homogeneous fashion (wavy slip), i.e., deformation at elevated temperature. This was attributed to the formation of dislocation cell structures with less extent of backstress formation. It is therefore most likely that backstresses relaxed to some extent during the soaking period, which may have been more pronounced in the more severely work-hardened material states. Despite the assumed occurrence of static strain aging, dynamic strain aging during elevated temperature deformation was only observed in terms of serrations in the non-swaged state. The effect can be attributed to the interaction of moving dislocations with diffusing interstitial elements, such as $\mathrm{C}$, and is strain rate and temperature dependent. ${ }^{[33,34]} \mathrm{At}$ increasing temperatures $\left(475^{\circ} \mathrm{C}\right.$ to $625{ }^{\circ} \mathrm{C}$ or approx. $750 \mathrm{~K}$ to $900 \mathrm{~K}$ ), substitutional elements such as $\mathrm{Cr}^{[32,33]}$ and $\mathrm{Nb}^{[34]}$ additionally contribute to the effect. The largely increased dislocation density (see above) after rotary swaging might allow for fast diffusion paths. ${ }^{[33]}$ Yet, deformation of rotary swaged Alloy 718 is devoid of serrations. The underlying effects will be subject to future investigations. 


\section{Correlation of Estimated Dislocation Density and Strength}

In Figures 13 and 14, selected flow stress values, derived from tensile and compression tests at various plastic strains are shown as a function of pre-deformation.

Due to the pronounced non-linearities found in the early deformation stage of compression tests of pre-deformed Alloy 718, the comparability of strength values obtained in tension and compression is severely limited. The non-linearities are expressed in a large spread between tensile and compressive stress values, particularly at room temperature. With increasing strain, the flow stresses in compression tend toward the flow stresses in tension. As discussed in the context of the Bauschinger effect above, backstresses partly relax during the soaking period, but permanent softening of the material seems to prevail regardless of testing temperature.

No attempts were made to quantitatively assess the ductility of the cold-worked material. However, preliminary tests had shown that fracture strain in ambient temperature tensile tests drop to values lower than 6 pct. Therefore, the tests at the highest pre-strains were interrupted already at approx. 5 pct total strain. Results by Praveen et al. ${ }^{[6,13]}$ indicate that fracture strain, measured to approx. 23 pct in the peak-aged condition, is almost halved by a 5 pct cold rolling treatment. This shows that small pre-deformation may be sufficient to embrittle the material. The fracture strain after a $20 \mathrm{pct}$ cold rolling treatment was approx. 7 pct. $^{[6]}$

Finally, the mechanical properties shall be combined with the the microstructural features assessed in previous sections. To this end, Figure 15 displays the correlation of the microhardness (see Table II) and strength values (see Figures 13 and 14) obtained in tension with the results of XRD analysis regarding the estimated magnitude of the dislocation density. Since the slope $m$ in the modified Williamson-Hall analysis in Figure 8(b) is proportional to the square root of estimated dislocation density (Eq. [3]), a linear

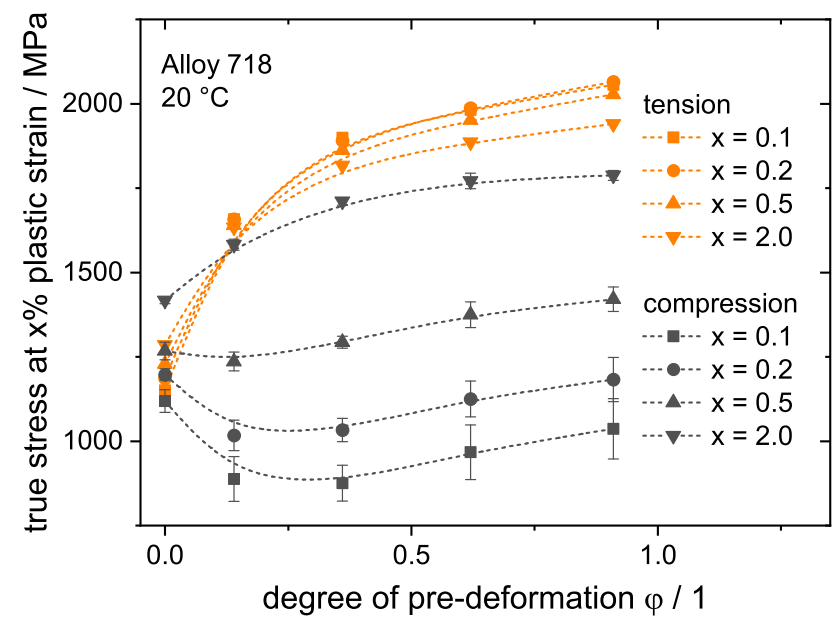

Fig. 13- True stress values at various offset plastic strains ( $x$ is given in pct), $20^{\circ} \mathrm{C}$. Connecting lines are to guide the eyes.

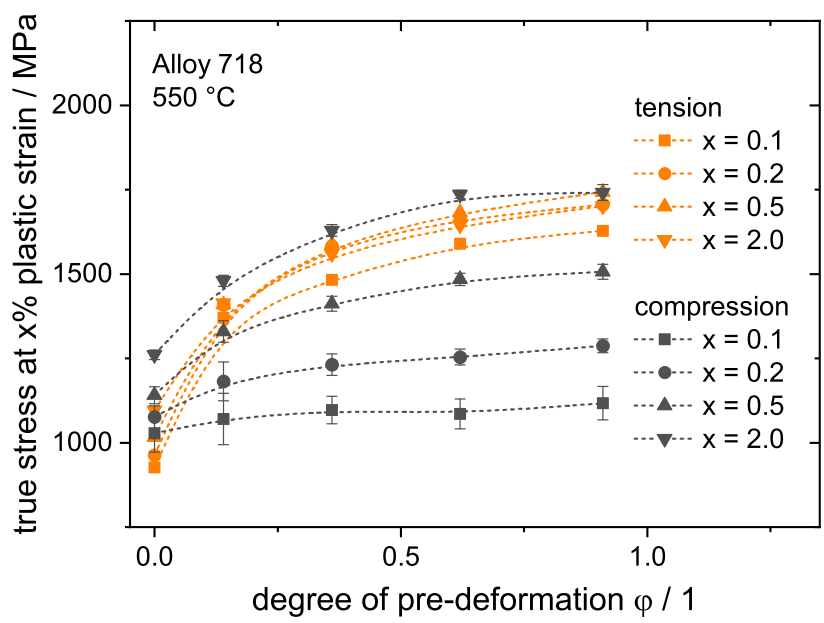

Fig. 14-True stress values at various offset plastic strains $(x$ is given in pct), $550{ }^{\circ} \mathrm{C}$. Connecting lines are to guide the eyes.

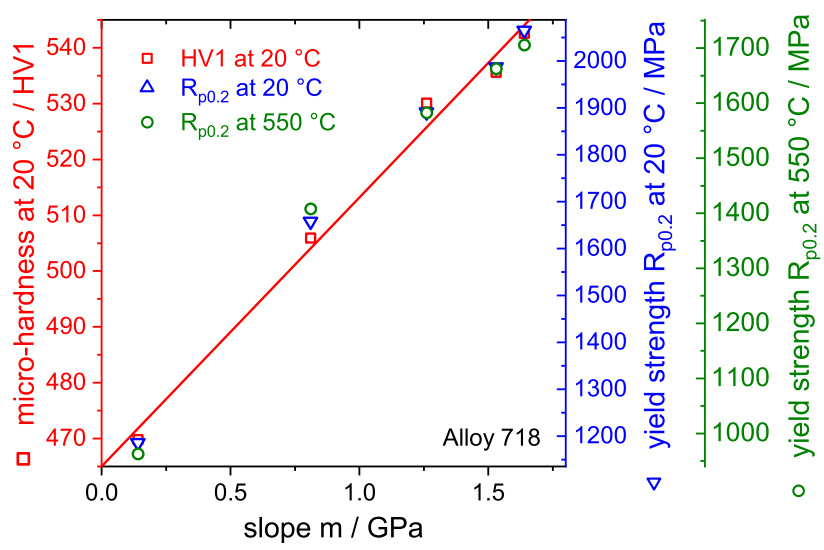

Fig. 15-Mechanical properties as a function of the slope $m$ extracted from the modified Williamson-Hall plots in Figure 8(b). Straight line indicates the fit function of both quantities from Table III. Axes for offset yield strengths $R_{\mathrm{p} 0.2}$ are adapted using the linear relations to microhardness in Table III.

correlation of microhardness or strength indicates a Taylor-type relation with dislocation density $\rho^{[35]}$.

$$
R_{p 0.2} \propto M G b \sqrt{\rho}
$$

$M$ and $G$ are the Taylor factor and the shear modulus, respectively. $m$ is used for the analysis instead of $\rho$ in order to evaluate the average changes between the different deformation states rather than the precise calculation of the absolute magnitude of the dislocation density which needs more information about the microstructural mock-up.

Indeed, linear fits as presented in Table III yield very good adjusted coefficients of correlation $R_{\text {adj }}^{2}$ very close to 1 for the present data, independent of the Taylor-type correlation of $m$ and $\mathrm{HV} 1$ or proportional scaling of hardness HV1 and strength data YS @ $20{ }^{\circ} \mathrm{C}$ and 550 ${ }^{\circ} \mathrm{C}$, respectively. Hence, strength seems to be governed by the increased dislocation density subsequent to rotary swaging. This holds true not only for room temperature but also for mechanical strength obtained at $550{ }^{\circ} \mathrm{C}$. The 
correlation function is still linear but at smaller slope in comparison to room temperature strength. Even when other offset strains are considered for strength determination, similar quality of linear fits is observed. This results from the rather weak strain-hardening observed in the tensile tests of the deformed material in Figures 9 and 10 .

\section{Effect of Tempering Treatment}

If cold working is the last processing step prior to service, it is worth to assess the material's response to service conditions, for instance, elevated temperatures which are relevant to aerospace applications. Therefore, a 100-hour tempering at $600{ }^{\circ} \mathrm{C}$ was carried out to emulate a (short) exposure in the order of the service temperature. The results of microhardness measurements on deformed and deformed and aged Alloy 718 are shown in Figure 16. A pronounced increase of microhardness due to tempering is obvious. The higher the pre-strain, the higher the additional hardness increase due to tempering.

Moreover, a small number of additional compression tests were carried out on severely pre-deformed $\left(\varphi_{4}=0.91\right)$ and aged material. Figure 17 shows the stress-strain relationships in tensile tests, compression tests, and compression tests after tempering treatment, which were carried out at $20^{\circ} \mathrm{C}$ and $550{ }^{\circ} \mathrm{C}$.

Obviously, the tempering treatment gives rise to full restoration of the elastic range in compression tests at ambient and elevated temperature. Moreover, the flow stresses exceed those observed in tension immediately after the onset of plastic deformation and are well beyond $2000 \mathrm{MPa}$. It is therefore concluded that apart from static strain aging, long-range residual stress fields (backstresses) might relax to a great extent during tempering, reducing both transient and permanent softening portions of the Bauschinger effect. Assuming planar deformation in Alloy 718 regardless of pre-strain, this would be an obvious contradiction to the results derived by Mataya et al. ${ }^{[30]}$ who postulated the necessity of wavy slip to suppress permanent softening (see above). Planar deformation was shown to prevail in rotary swaged Alloy 718 up to $\varphi=0.62$ in a recent study. ${ }^{[19]}$ Possibly, the suppression of the Bauschinger effect is limited to high degrees of work-hardening and high tempering temperatures, where pronounced stress relaxation is expected to occur. ${ }^{[17,27]}$ Yet, it is still not clear which further contributions to this effect might prevail in Alloy 718. Blankenship and Henry ${ }^{[36]}$ carried

Table III. Linear Interrelations of Properties, Slope $m$ in Pa in Modified Williamson-Hall Plots, Vickers Microhardness at RT as HV1, Off-set Yield Strengths $R_{\mathrm{p} 0.2}$ in MPa at $20^{\circ} \mathrm{C}$ and $550{ }^{\circ} \mathrm{C}$

\begin{tabular}{llc}
\hline Relation & \multicolumn{1}{c}{ Formula } & $R_{\mathrm{adj}}^{2}$ \\
\hline$m-\mathrm{HV} 1$ & $465+4.8 \cdot 10^{-8} \mathrm{~m}$ & 0.986 \\
$\mathrm{HV} 1-\mathrm{YS} @ 20{ }^{\circ} \mathrm{C}$ & $-4397+11.91 \mathrm{HV} 1$ & 0.995 \\
$\mathrm{HV} 1-\mathrm{YS} @ 550{ }^{\circ} \mathrm{C}$ & $-3775+10.14 \mathrm{HV} 1$ & 0.984 \\
\hline
\end{tabular}

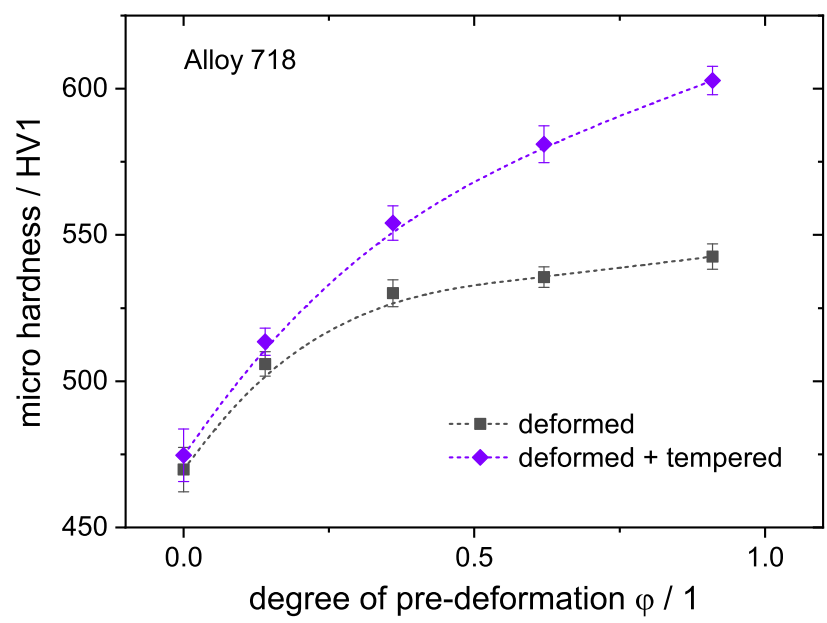

Fig. 16-Influence of 100 hours $/ 600{ }^{\circ} \mathrm{C}$ tempering treatment on microhardness.

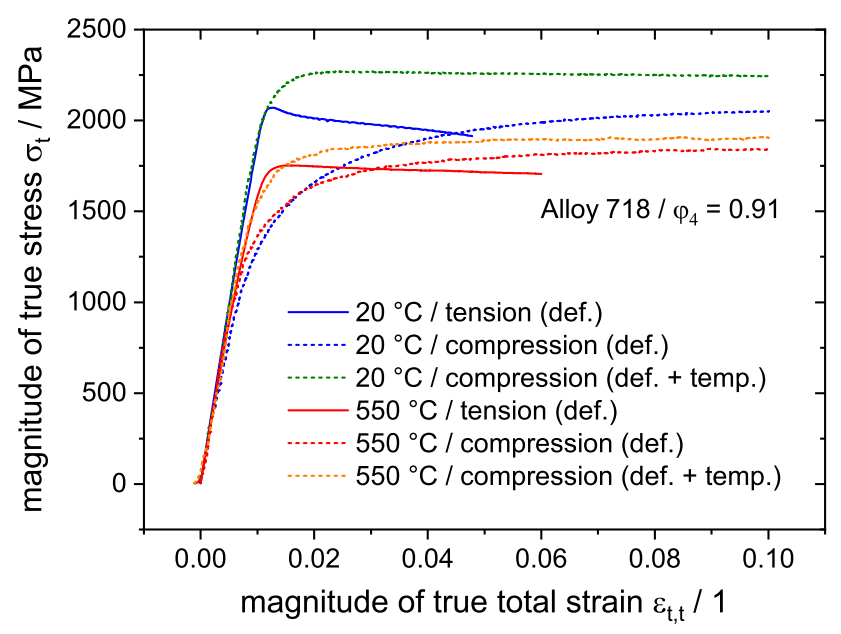

Fig. 17-Influence of 100 hours $/ 600{ }^{\circ} \mathrm{C}$ tempering treatment on compressive behavior after severe $\left(\varphi_{4}=0.91\right)$ pre-deformation.

out tempering tests on direct aged and subsequently cold-deformed Alloy 718. In their study, specimens were pre-strained by 30 pct in compression and subsequently tempered for 24 hours at $538{ }^{\circ} \mathrm{C}(811 \mathrm{~K})$. Comparing tensile test results after compression to tensile test results after compression with subsequent tempering, they found the yield stress increased by more than 70 pct and the fracture strain decreased by 80 pct due to the tempering treatment after the compression step. The Bauschinger effect was not assessed in their study. The general effects were confirmed by Praveen et al. ${ }^{[6]}$ after a stress-relief treatment, though. In the present study, the effects of tempering on the precipitate scale were not investigated. Using isochronal DSC analysis, Mei et al. ${ }^{[3]}$ found the onset of $\gamma^{\prime \prime}$-formation in solution-annealed Alloy 718 to be shifted from approx. $750{ }^{\circ} \mathrm{C}$ to approx. $680{ }^{\circ} \mathrm{C}$ and approx. $640{ }^{\circ} \mathrm{C}$ when the aging treatment was preceded by cold rolling with 25 and 70 pct thickness reduction, respectively. A shift to even 
lower temperatures in more heavily deformed material is therefore conceivable. Furthermore, cold work promotes the formation of $\delta$-phase. ${ }^{[3,11,37]}$ In an early work on fatigue crack growth in precipitation-strengthened Alloy 718, Clavel et al. ${ }^{[37]}$ took advantage of this effect, using $\delta$-precipitates as markers of the monotonic plastic zone at the crack tip. According to their work, plastic strains around 1 pct or lower could be visualized by means of an 80-hour tempering treatment at $670{ }^{\circ} \mathrm{C}$. Future studies should deal in more detail with such effects. Although not directly assessed in our study, it is obvious that tempering, besides largely increasing the microhardness, restoring the elastic behavior and suppressing the Bauschinger effect, embrittles the material. According to the review of Zheng et al ${ }^{[38]}$ on medium temperature $\left(500{ }^{\circ} \mathrm{C}\right)$ embrittlement in Ni-based superalloys, non-equilibrium grain boundary segregation of elements such as sulfur and phosphorus is proposed to be the main cause of the observed effect, though the influence of strain aging may possibly not be ruled out. ${ }^{[36]}$ However, it becomes clear that cold work, if the last processing step prior to service, should be limited to a minimum.

\section{CONCLUSIONS}

In the present study, the influence of cold rotary swaging on the microstructure and uniaxial mechanical behavior of precipitation-hardened Alloy 718 was investigated. The following conclusions can be drawn:

- Rotary swaging of Alloy 718 up to deformation degrees of $\varphi=0.91$ caused an increase in microhardness from approx. $470 \mathrm{HV} 1$ to approx. 543 HV1, which corresponds to an increase by 15.5 pct.

- EBSD analysis revealed large misorientations close to grain boundaries and the formation of a fiber texture after pre-deformation.

- Stress properties in tension were enhanced markedly due to work-hardening. In compression, a transient stress-strain evolution was found and could be rationalized in terms of the Bauschinger effect.

- Mechanical strength in tension and microhardness subsequent to rotary swaging perfectly correlate with increasing dislocation density in the form of a Taylor-like relationship for dislocation densities estimated by XRD.

- Post-swaging tempering for 100 hours at $600{ }^{\circ} \mathrm{C}$ had an increasing effect on microhardness with increasing pre-deformation. The tempering treatment markedly reduces the Bauschinger effect but may result in an embrittlement of the material.

\section{ACKNOWLEDGMENTS}

The authors gratefully acknowledge financial support of this study by the German Research Foundation (DFG) with the grant number SCHU 1010/53-1.
This work was partly carried out with the support of the Karlsruhe Nano Micro Facility (KNMF, www.kn mf.kit.edu), a Helmholtz Research Infrastructure at Karlsruhe Institute of Technology (KIT, www.kit.edu).

\section{CONFLICT OF INTEREST}

The authors declare that they have no conflict of interest.

\section{FUNDING}

Open Access funding enabled and organized by Projekt DEAL.

\section{OPEN ACCESS}

This article is licensed under a Creative Commons Attribution 4.0 International License, which permits use, sharing, adaptation, distribution and reproduction in any medium or format, as long as you give appropriate credit to the original author(s) and the source, provide a link to the Creative Commons licence, and indicate if changes were made. The images or other third party material in this article are included in the article's Creative Commons licence, unless indicated otherwise in a credit line to the material. If material is not included in the article's Creative Commons licence and your intended use is not permitted by statutory regulation or exceeds the permitted use, you will need to obtain permission directly from the copyright holder. To view a copy of this licence, visit http://creat ivecommons.org/licenses/by/4.0/.

\section{REFERENCES}

1. D. Fournier and A. Pineau: Metall. Trans. A, 1977, vol. 8A, pp. 1095-105.

2. J.J. Debarbadillo and S.K. Mannan: JOM, 2012, vol. 64 (2), pp. 265-70.

3. Y. Mei, Y. Liu, C. Liu, C. Li, L. Yu, Q. Guo, and H. Li: J. Alloys Compd., 2015, vol. 649, pp. 949-60.

4. Y. Lin, D.G. He, M.S. Chen, X.M. Chen, C.Y. Zhao, X. Ma, and Z.L. Long: Mater. Des., 2016, vol. 97, pp. 13-24.

5. Y.T. Chen, A.C. Yeh, M.Y. Li, and S.M. Kuo: Mater. Des., 2017, vol. 119, pp. 235-43.

6. K. Praveen, G. Sastry, and V. Singh: Metall. Mater. Trans. A, 2008, vol. 39A, pp. 65-78.

7. S. Kalluri, K. Rao, G. Halford and M. McGaw. In: Superalloys 718, 625, 706 and Various Derivatives, 1997, pp. 595-606.

8. H. Zhang, C. Li, Q. Guo, Z. Ma, Y. Huang, H. Li, and Y. Liu: Mater. Sci. Eng. A, 2018, vol. 722, pp. 136-46.

9. J. Oblak, D. Paulonis, and D. Duvall: Metall. Trans., 1974, vol. 5, pp. $143-53$

10. S. Kalluri, K.B.S. Rao, G.R. Halford, and M. McGaw. In: Superalloys 718, 625, 706 and Various Derivatives, 1994, pp. 593-606.

11. W. Liu, F. Xiao, M. Yao, Z. Chen, Z. Jiang, and S. Wang: Scripta Mater., 1997, vol. 37 (1), pp. 53-57.

12. W. Liu, M. Yao, and Z. Chen: Metall. Mater. Trans. A, 1999 , vol. $30 \mathrm{~A}$, pp. $31-40$.

13. K. Praveen and V. Singh: Metall. Mater. Trans. A, 2008, vol. 39A, pp. 79-86. 
14. B.J. Bond and R.L. Kennedy. In: Sixth International Special Emphasis Symposium on Superalloys 718, 625, 706 and Derivatives, 2006, pp. 203-11.

15. F.Z. Utyashev, R. Mulyukov, R. Sukhorukov, and V. Valitov: Mater. Sci. Forum Trans. Tech. Publ., 2016, vol. 838, pp. 615-20.

16. V. Schulze: Modern Mechanical Surface Treatment: states, stability, effects, Wiley, New York, 2006.

17. P.S. Prevéy: In: Proceedings of the 2nd ASM Materials Solutions Conference \& Exposition, 2000, pp. 426-34.

18. P.C. Yadav, S. Sahu, A. Subramaniam, and S. Shekhar: Mater. Sci. Eng. A, 2018, vol. 715, pp. 295-306.

19. A. Klumpp, S. Maier, H. Chen, M. Fotouhi, R. Schneider, S. Dietrich, K.H. Lang, and V. Schulze: Int. J. Fatigue, 2018, vol. 116 , pp. 257-67.

20. D. Worthem, I. Robertson, F. Leckie, D. Socie, and C. Altstetter: Metall. Trans. A, 1990, vol. 21A, pp. 3215-20.

21. L. Xiao, D. Chen, and M. Chaturvedi: Scripta Mater., 2005, vol. 52 (7), pp. 603-607.

22. U.F. Kocks, C.N. Tomé, and H.R. Wenk: Texture and Anisotropy: Preferred Orientations in Polycrystals and their Effect on Materials Properties, Cambridge University Press, Cambridge, 2000.

23. A. Benghalem and D. Morri: Acta Metall. Mater., 1994, vol. 42, pp. 4071-81.

24. C. Kumara, D. Deng, J. Moverare, and P. Nylén: Mater. Sci. Technol., 2018, vol. 34 (5), pp. 529-37.

25. G.K. Williamson and R.E. Smallman: Philos. Mag., 1956, vol. 1 (1), pp. 34-46.

26. P.J. Withers and H. Bhadeshia: Mater. Sci. Technol., 2001, vol. 17 (4), pp. 366-75.

27. J. Hoffmeister, V. Schulze, R. Hessert, and G. Koenig: Int. J. Mater. Res., 2012, vol. 103 (1), pp. 66-72.
28. A. Franceschi, J. Stahl, C. Kock, R. Selbmann, S. Ortmann-Ishkina, A. Jobst, M. Merklein, B. Kuhfuß, M. Bergmann, B.A. Behrens et al:: Arch. Appl. Mech., 2021, https://doi.org/ 10.1007/s00419-021-01903-7.

29. C.C. Li, J. Flasck, J. Yaker, and W. Leslie: Metall. Trans. A, 1978, vol. 9A, pp. 85-89.

30. M. Mataya, M. Carr, and G. Krauss: Mater. Sci. Eng., 1983, vol. 57 (2), pp. 205-22.

31. M. Richards, C. Van Tyne, and D. Matlock: Mater. Sci. Eng. A, 2011, vol. 528 (27), pp. 7926-32.

32. S. Semiatin, P. Fagin, B. Streich, R. Goetz, and V. Venkatesh: In: Proceedings of the 9th International Symposium on Superalloy 718 \& Derivatives: Energy, Aerospace, and Industrial Applications, Springer, 2018, pp. 957-75.

33. C. Hale, W. Rollings, and M. Weaver: Mater. Sci. Eng. A, 2001, vol. 300 (1-2), pp. 153-64.

34. S. Nalawade, M. Sundararaman, R. Kishore, and J. Shah: Scripta Mater., 2008, vol. 59 (9), pp. 991-94.

35. G.I. Taylor: Proc. R. Soc. Lond. Ser. A, 1934, vol. 145, pp. 362-87.

36. C. Blankenship, Jr and M. Henry: Scripta Mater., 1996, vol. 34 (9), pp. 1461-66.

37. M. Clavel, D. Fournier, and A. Pineau: Metall. Mater. Trans. A, 1975, vol. 6A, pp. 2305-307.

38. L. Zheng, G. Schmitz, Y. Meng, R. Chellali, and R. Schlesiger: Crit. Rev. Solid State Mater. Sci., 2012, vol. 37 (3), pp. 181-214.

Publisher's Note Springer Nature remains neutral with regard to jurisdictional claims in published maps and institutional affiliations. 